\title{
Späne sammeln beim Aufbohren von verklemmten Schraubenköpfen
}

Markus Piller, Andrea Rodig, Dankward Höntzsch
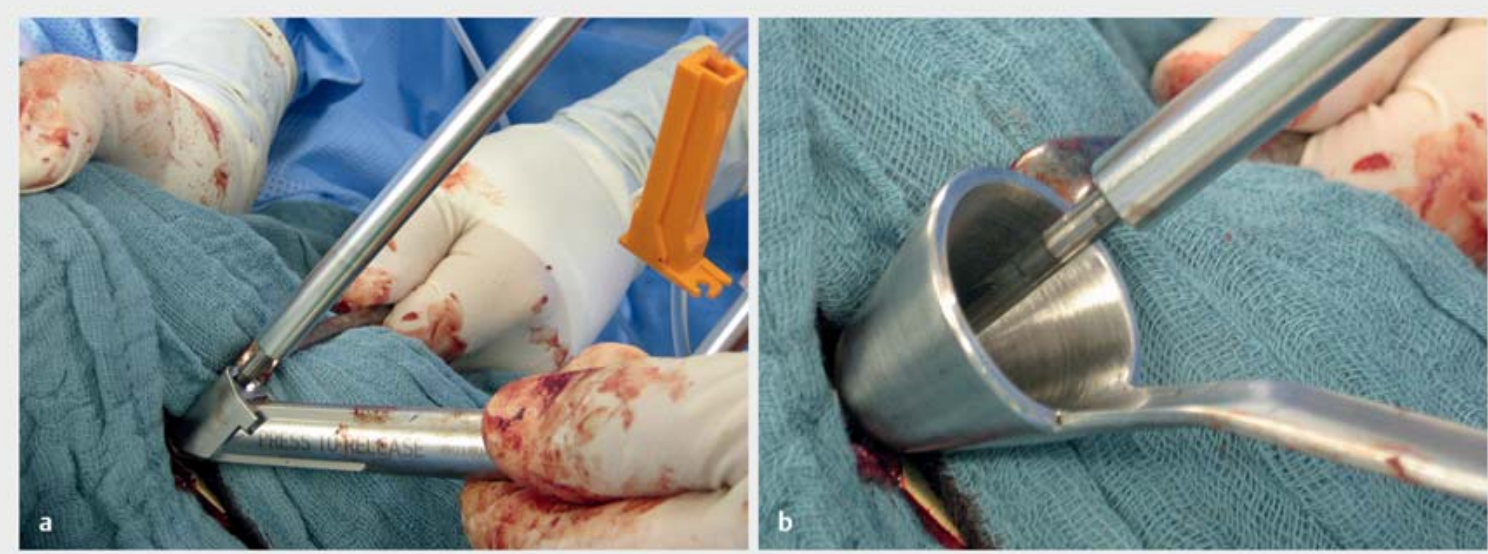

- Abb. 1 (a) Spülsauginstrument, (b) Ohrtrichter.

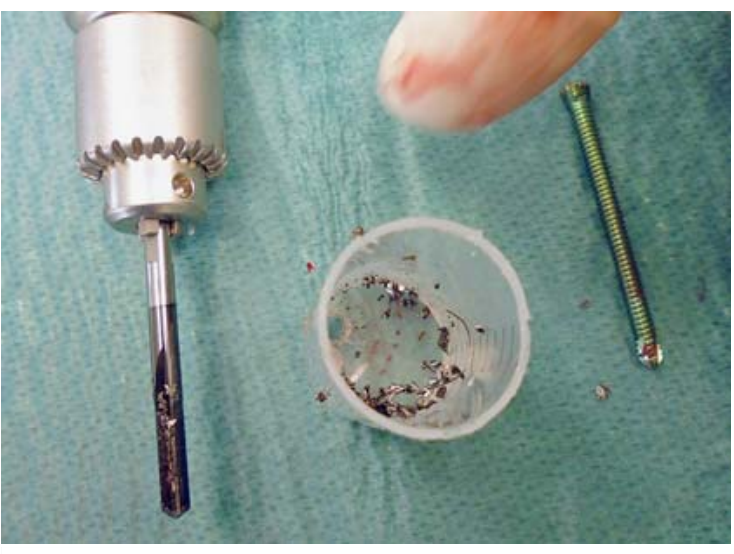

- Abb. 2 Verwendung einer Spritze.

Wenn alle Techniken nicht helfen, müssen bei der Metallentfernung von Platten und Schrauben manchmal die Schraubenköpfe in den Platten aufgebohrt werden.

In den meisten Fällen steht dann leider das Spül-SaugInstrument $(\triangleright$ Abb. $\mathbf{1}$ a) oder ein Ohrtrichter ( $\vee$ Abb. $\mathbf{1}$ b) nicht zur Verfügung.

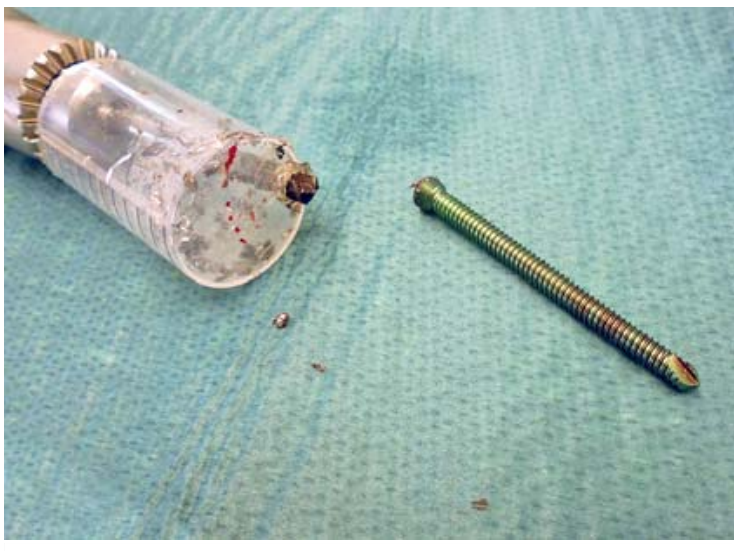

- Abb. 3 Bohrung durch den Kanülenansatz.

Dann hilft genauso gut folgender Trick:

- Man verwendet eine 10-ml- oder 20-ml-Spritze, schneidet diese in 1-2 cm Entfernung vom Kanülenansatz quer ab ( $\triangleright$ Abb. 2).

- Dann bohrt man mit dem ausgesuchten Bohrer (Carbide oder HSS) durch den Kanülenansatz ( $\triangleright$ Abb. $\mathbf{3}$ ).

- Jetzt setzt man das Ganze wie einen Trichter möglichst eng auf die Zone zwischen Plattenlochrand und Schraubenkopf. Dann werden beim Aufbohren des 


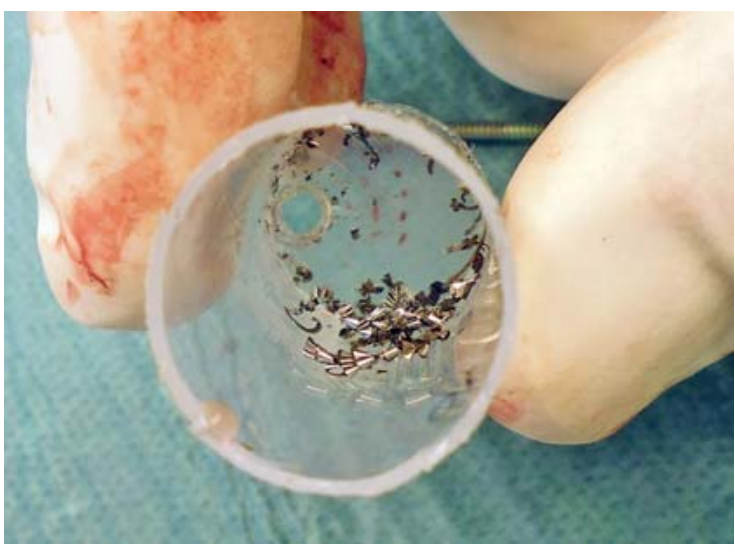

- Abb. 4 Sammeln der Späne im Spritzenkörper.

Schraubenkopfs alle Späne im Spritzenkörper wie in einem Trichter gesammelt ( $\bullet$ Abb. 4).

Je gewissenhafter man dies macht und je dichter der „Spritzentrichter" anliegt, umso besser werden tatsächlich alle Späne gesammelt und landen nicht im Gewebe!
In der Klinik Gut in St. Moritz und in der BG Unfallklinik Tübingen (mit Prof. Höntzsch) hat sich dieses Vorgehen mehrfach bewährt.

\section{Merke}

Bitte senden Sie Ihre Tipps und Tricks ein, damit dies ein lebendiger Austausch wird und wir voneinander lernen können. Bitte an: op-journal@thieme.de oder Georg Thieme Verlag KG, OP-Journal, z. Hd. Frau Stickel, Rüdigerstraße 14, 70469 Stuttgart.

\section{Korrespondenzadresse}

\section{Prof. Dr. Dankward Höntzsch}

Tübingen

hoentzsch@t-online.de

\section{Bibliografie}

DOI http://dx.doi.org/10.1055/s-0043-107063 OP-JOURNAL 2017; 33: 80-81 @ Georg Thieme Verlag KG Stuttgart · New York ISSN 0178-1715 